\title{
José Damião Rodrigues: Histórias Atlânticas. Os Açores na primera modernidade
}

Colecção Estudos \& Documentos, 13. Centro de História de Além-Mar, Faculdade de Ciências Sociais e Humanas-Universidade Nova de Lisboa e Universidade dos Açores. Ponta Delgada, 2012. 246 páginas. ISBN: 978-989-8492-10-4

El presente libro es, según nos explica el autor en la nota previa, fruto de una meditada decisión de aglutinar varios trabajos publicados con anterioridad, cuyo eje vertebrador, conceptual y geográfico, es el ámbito atlántico. Los doce estudios han sido organizados en tres secciones basadas en una secuencia temática y cronológica.

La primera sección, Da Geografia, se compone de cuatro artículos que tratan la cuestión de la localización y de las representaciones geográficas de las islas atlánticas y su papel en la génesis de la primera modernidad. En el primero, A experiencia insular: modelos políticos e sociais na primera modernidade, la idea central es analizar y reivindicar la labor pionera de las islas en el proceso de formación del mundo atlántico $\mathrm{y}$, por ende, en el propio proceso de la creación de la primera modernidad. El profesor Rodrigues demuestra como el dominio de los archipiélagos atlánticos supuso el inicio de la expansión ultramarina ibérica, situándolos en el eje central del nuevo circuito marítimo, y cómo las islas se convirtieron en una especie de laboratorios, donde las coronas ibéricas experimentaron y ensayaron las fórmulas para la dominación de las nuevas tierras descubiertas, en una especie de «operación fundadora de modernidad». En el segundo, Um arquipélago de Geometria variável: representações dos Açores no período Moderno (séculos XVI-XVIII), a través del análisis de varios textos históricos, tanto de isleños como de extranjeros de los siglos modernos, se argumenta la coexistencia de distintas representaciones y percepciones de la realidad geográfica, política, económica y social azoriana que relativizan la proyección de un concepto integrador de región para las Azores en la Edad Moderna. En el tercer estudio, «Off the Islands»: Os Açores no contexto da primera expansão inglesa, se constata la importancia geoestratégica de las Azores en la expansión ultramarina europea, lo que también implicó su participación en las rivalidades imperiales por el dominio marítimo. En esta ocasión, a partir de testimonios de autores ingleses de finales del siglo XVI y principios del XVII, se explica cómo el archipiélago portugués se convirtió en un espacio de aprendizaje de nuevas estrategias y dinámicas imperiales para la Inglaterra isabelina. 
En este trabajo podremos conocer las relaciones mercantiles y bélicas establecidas entre las Azores e Inglaterra, desde los siglos bajomedievales, pasando por los años conflictivos de la Unión Ibérica, hasta llegar a principios del seiscientos con la firma del Tratado de Paz entre Inglaterra y la monarquía hispánica, que supuso una notoria entrada de comerciantes ingleses en las principales plazas azorianas. El último estudio, Entre ficcão e realidade: O Faial e as ilhas do grupo central no relato da segunda viagem de James Cook, es una muestra de cómo realizar una crítica histórica y constructiva a la llamada «literatura de viajes», tomando como referente la imagen proyectada de las islas centrales del archipiélago de las Azores en el relato del viaje de James Cook, realizado entre 1772 y 1775, y compararla no sólo con otras fuentes coetáneas, sino también con la historiografía y documentación relativa a ese periodo. A través de este análisis comparativo, se realiza una rica y detallada exposición de datos históricos, geográficos, demográficos, administrativos, militares y socioeconómicos de las islas centrales más acordes con la realidad de la segunda mitad del setecientos.

En la segunda sección, Da Sociedade, los seis trabajos reunidos son el resultado de la principal línea de investigación del profesor Rodrigues, dedicada a los grupos y las dinámicas sociales, con particular atención a las élites locales. El primer estudio, Nobrezas locais e apropriação do espaço: a vinculação em São Miguel no reinado de D. Manuel, explica que en el reinado manuelino (1495-1521) se produjo la división de las Azores en islas de realengo (las centrales y orientales) y de señorío (las islas occidentales). En relación a este hecho, se analiza cómo se inició en la isla de São Miguel -la mayor y principal de las islas orientales- dos procesos complementarios: por un lado, la definición del cuadro concejil micaelense, con la creación de varias villas, fruto del diseño de una red de administración municipal que favoreció la configuración de varias noblezas locales. Por otro, el punto de partida del movimiento de vinculación de la propiedad, instrumento nobiliario por excelencia para la apropiación del espacio y de la consolidación patrimonial, con la institución de los morgadios y capelas. En el segundo trabajo, Elites locais e redes de poder em São Miguel no século XVI: O testemunho de Gaspar Frutuoso, a través de la crónica del sacerdote micaelense Gaspar Frutuoso (1522-1591), se identifica uno de los factores que consolidaron el poder de las noblezas municipales que, aparte de monopolizar los oficios concejiles, era dominar los cargos superiores de las companhias de ordenanças, una institución militar local para la defensa de los pueblos, en el reino y en el imperio, que se convirtió en un importante mecanismo tanto de promoción social como de refuerzo del poder político y social. En esta ocasión, Rodrigues ha tomado en consideración cuatro trayectorias vitales que ilustran la práctica continuada de relaciones endogámicas y consanguíneas y de refuerzo de alianzas, que dieron lugar a la creación de redes familiares y clientelares que se vinculaban y diseminaban por toda la isla, dando lugar a la formación de unas dinastías en el quinientos que se perpetuaron en las siguientes centurias. En el tercer artículo, Entre duas margens: A circulação atlântica dos açorianos nos séculos $X V I I$ e XVIII, a partir de varios ejemplos, tanto individuales como colectivos, se ha trazado el itinerario de la movilidad atlántica de los isleños, que en algunos casos fue un fenómeno de doble sentido, es decir, de salida de las islas pero también de retorno, 
de la misma persona o de sus descendientes. También podemos conocer los móviles de distinta índole que propiciaron el desplazamiento de los azorianos, como era el espíritu religioso y evangelizador, los servicios a la Corona, o el anhelo de alcanzar una prosperidad socioeconómica en tierras brasileñas. Todo ello sin olvidar a los hombres del mar, aquellos isleños que formaban parte de las tripulaciones de los barcos que surcaban las dos orillas del Atlántico. El cuarto estudio, Orgânica militar e estruturação social: Companhias e oficiais de ordenança em São Jorge (séculos XVI-XVIII), analiza el origen, evolución, composición y competencias de las companhias de ordenanzas como un cuerpo militar local estructurado y definido por sucesivas legislaciones. A partir del ejemplo de la isla de São Jorge, el profesor Rodrigues nos muestra como las oligarquías locales se apropiaron progresivamente de los principales cargos militares desde su institución en el siglo XVI; cómo fue el desempeño y funciones de los oficiales y los conflictos que surgieron entre ellos, y cómo esas mismas oligarquías minimizaron los intentos de reforma y control de la monarquía. Esta es una idea importante, que pone en relieve la continuidad en el poder de las noblezas locales y el fracaso de algunas reformas de la Corona, algunas de Sebastião José de Carvalho e Melo, marqués de Pombal, en la segunda mitad del setecientos. En el quinto trabajo, De mercadores a terratenentes: percursos ingleses nos Açores (séculos XVII-XVIII), se establece el marco general de las relaciones comerciales de los ingleses con las Azores desde finales del siglo XV hasta principios del XVIII. A continuación, tras mostrar la trayectoria vital de tres familias inglesas de origen mercantil radicadas en las islas desde el siglo XVII -Stone, Chamberlain y Fisher-, el autor ha podido fijar algunas de sus pautas generales de comportamiento y sus estrategias de ascenso e integración en la sociedad insular. En el último artículo que cierra la sección, As elites locais nos Açores em finais do Antigo Regime, se trata de esclarecer la composición social de las noblezas municipales de la isla de São Miguel en el setecientos y se argumenta la operatividad del método de la micro-historia para identificar las diferencias que se diluyen bajo la aparente homogeneización dada por la utilización de categorías generales. Así, tras el acopio de una gran cantidad de datos relativos a cada actor social, con el estudio minucioso de las diferentes categorías sociales atribuidas en la documentación local a los oficiales municipales y del cruce de fuentes, Rodrigues ha podido verificar que «não havia uma fisionomía social única da nobreza micaelense, porque, de facto, não existía uma, mas sim varias nobrezas ou, se quisermos, varios níveis de honra, poder e riqueza dentro do corpo nobiliárquico micaelense».

La tercera sección, Do Reformismo Setecentista, se compone de dos textos donde se aborda de forma crítica la problemática de las reformas introducidas en las Azores durante el XVIII y la de sus intérpretes. En el primer trabajo, "Para o socego e tranquilidade publica das ilhas»: Fundamentos, ambição e limites das reformas pombalinas nos Açores, el punto de partida es una crítica razonada al concepto de una «modernidade pombalina» y un recorrido bibliográfico que analiza algunas interpretaciones acerca de la modernidad y del despotismo ilustrado. A continuación, se examina minuciosamente un conjunto de textos relativos a las reformas que el futuro marqués de Pombal implantó en las Azores en 1766, para concluir que los principios que orienta- 
ron los cambios introducidos obedecían a la razón de Estado y a la noción de «Estado policía» y no tanto a una orientación innovadora. Además, para Rodrigues, el análisis del fracaso de algunas de esas medidas y de la capacidad de resistencia de las élites azorianas a la tentativa de introducir un mayor control del centro político sobre las periferias insulares, contribuye a relativizar las lecturas tradicionales en relación al impacto de toda la actividad reformista del Secretario de Estado del rey José I. En el segundo trabajo, Percursos de um magistrado nos Açores: A etapa açoriana de José Acúrsio das Neves, el profesor Rodrigues aplica una propuesta que enunció en el trabajo anterior; pues trata de saber si se puede encontrar en el pensamiento y la práctica administrativa de un determinado autor las ideas que después serán enunciadas en su producción intelectual. En esta ocasión, el objeto de estudio es José Acúrsio das Neves, uno de los más destacados economistas portugueses del primer cuarto del siglo XIX, que comenzó su cursus honorum como juiz de fora de la ciudad de Angra y después fue corregidor de la misma demarcación. Además de estudiar los conflictos que José Acúrsio das Neves mantuvo con el gobernador de las Azores, el autor revela, a través del análisis de la documentación producida por Neves en el desempeño de su función pública, que su actuación se distinguió de la gestión de las élites locales en términos de la organización de la vida pública, lo que constata que Neves era partidario de algunos principios, como la libertad de comercio, que posteriormente defendería en alguna de sus obras doctrinarias.

Con la lectura del libro Histórias Atlânticas. Os Açores na primera modernidade, nos encontramos ante un sólido producto del oficio de historiador. José Damião Rodrigues aúna el dominio y comprensión de un vasto conjunto teórico con una metodología precisa de análisis e interpretación de una variada y rica base documental. En estos doce estudios, el profesor Rodrigues ha sabido plasmar con coherencia el objeto de investigación y acerca al lector a la dimensión geográfica, económica y política de las Azores en los siglos Modernos, con un significativo aporte al conocimiento de la génesis y los modelos de reproducción social de las élites. También valoramos su contribución a desvelar y proporcionar nuevas líneas de investigación que, sin duda, ayudarían a completar y perfeccionar nuestro conocimiento histórico sobre el reino de Portugal. En definitiva, el libro supone una novedosa e interesante contribución para el enriquecimiento de la llamada historia atlántica, pero también para establecer patrones de comparación y conectividad, en especial con el caso español, en la línea de la world history y de la global history.

Mar García Arenas

Universidad de Alicante 